\title{
HLA association with dermatitis herpetiformis is accounted for by a cis or transassociated DQ heterodimer
}

\author{
M A Hall, J S S Lanchbury, W J Bolsover, K I Welsh, P J Ciclitira
}

\begin{abstract}
HLA-DR, DQ, and DP restriction fragment genotyping was undertaken in 23 dermatitis herpetiformis patients and 53 healthy control subjects. HLA-DQw2 was present in $100 \%$ of patients with dermatitis herpetiformis (23 of 23) versus $40 \%$ of control subjects ( 21 of 53 ). Significant secondary associations occurred with HLA-DR3 (91\% of patients versus $28 \%$ of control subjects) and DPw1 (39\% of patients versus $11 \%$ of control subjects). Dermatitis herpetiformis and coeliac disease thus share an identical HLA class II association. It is likely that HLA class II genes directly influence the immune responses leading to mucosal damage in both diseases. The strongest candidate for disease susceptibility to dermatitis herpetiformis is DQw2. The HLA molecule most likely to be involved in coeliac disease is a specific $D Q \alpha / D Q \beta$ heterodimer, encoded in cis arrangement in DR3 haplotypes or in trans arrangement in a DR5, 7 genotype. Our data on dermatitis herpetiformis patients fits this model perfectly. All these patients are capable of expressing this molecule, which may be responsible for the gluten sensitive enteropathy seen in a subgroup of patients with dermatitis herpetiformis and coeliac disease.
\end{abstract}

The common classic form of dermatitis herpetiformis is characterised by an itchy blistering skin eruption and granular IgA deposits at the dermoepidermal junction in an area not affected by the rash. Patients with classic dermatitis herpetiformis may exhibit gluten sensitive enteropathy, and the disease is associated with particular HLA class I and class II antigens. A less frequent form (seen in 10-15\% of patients) is distinguished by linear $\operatorname{IgA}$ deposits at the dermoepidermal junction. This latter group have a normal or minimally abnormal intestinal mucosa and a normal or only slightly increased prevalence of particular HLA antigens. Because there is some controversy over whether this group is a subtype of dermatitis herpetiformis or a different disease altogether, these patients have been excluded from the study. Most patients with the classic form of dermatitis herpetiformis have no overt gastrointestinal symptoms. Gastrointestinal morphology is essentially identical to that seen in patients with ordinary coeliac disease, albeit less severe and more patchy.'

Previous serological studies point to the importance of a locus in the human major histocompatibility complex in determining susceptibility to dermatitis herpetiformis. HLA class I antigens $\mathrm{A} 1$ and $\mathrm{B} 8$ were initially shown to be associated with dermatitis herpetiformis. ${ }^{2-+}$ Recent studies, however, suggest that the HLA class II antigens HLA-DR3 and DQw2 are more strongly associated with the disease. ${ }^{5-8}$ These data indicate that the primary association of dermatitis herpetiformis is with the HLA class II region which includes loci encoding $D R, D Q$, and DP antigens. Any class I association is probably due to linkage disequilibrium. An identical association with the HLA-DR3 DQw2 haplotype has also been documented in coeliac disease. ${ }^{910}$ A role for HLA in dermatitis herpetiformis is further suggested by comparisons of racial incidence versus HLA antigen frequency. This disease is very rare in Japan where the HLA B8 DR3 haplotype is almost absent in the normal population."

Recent evidence strongly implicates the HLADP subregion in susceptibility to coeliac disease..$^{12-14} \mathrm{We}$ and other investigators have shown that an extended HLA-DR3 haplotype including DPwl is raised in coeliac disease. ${ }^{1516}$ Using primed lymphocyte typing it has been shown that this extended haplotype is also highly represented in dermatitis herpetiformis. ${ }^{8}$

\section{Patients and methods}

Twenty three unrelated white patients with dermatitis herpetiformis were selected on the basis of clinical and histological features of the disease and the presence of granular deposits of IgA in an area of the skin not affected by blistering. All patients had clinical or histological features, or both, of gluten sensitive enteropathy, ranging from total villous atrophy to a raised intraepithelial lymphocyte count. Controls were 53 healthy unrelated white subjects without any evidence of dermatitis herpetiformis. Patients and control subjects were typed for HLA-DR, $D Q$, and DP antigens using restriction fragment length polymorphism analysis.

GENOTYPING BY RESTRICTION FRAGMENT LENGTH POLYMORPHISM ANALYSIS

Genomic DNA was extracted from whole blood. Altogether $10 \mu \mathrm{g}$ DNA were digested with 50 units of restriction enzymes TaqI and MspI according to the manufacturers instructions (Gibco BRL). Digested DNA was electrophoresed on $0.6 \%$ agarose gels for 16 hours at 60 $\mathrm{v}$ (TaqI digested DNA) or $40 \mathrm{v}$ (MspI digested DNA). Gels were Southern blotted onto Hybond- $\mathrm{N}$ according to manufacturers instructions (Amersham).

Probes used were a DRB1 SacI/Hind III 
fragment of PII- $\beta-4,{ }^{17}$ a DQB1 Aval fragment of pII- $\beta-1,{ }^{18}$ a DQA1 ApaI fragment of PII- $\beta-5,{ }^{19}$ a DPB1 RsaI-HpaI fragment of p11 $\beta-7,{ }^{20}$ and a DPA1 EcoRI fragment of pDA $\alpha 13 b .{ }^{21}$ The probes were ${ }^{32} \mathrm{P}$ oligolabelled to specific activities of $3-5 \times 10^{9}$ counts per minute per $\mu \mathrm{g}$ DNA. Filters were prehybridised, hybridised, and washed at $65^{\circ} \mathrm{C}$ according to standard methods (Amersham) and autoradiographed on for one to seven days. TaqI filters were hybridised with DRB1, DQB1, DQA1, and DPA1 while MspI filters were hybridised with DPB1.

POLYMERASE CHAIN REACTION AMPLIFICATION OF GENOMIC DNA

Amplification of DNA was based on the procedure of Saiki et al. ${ }^{22}$ For a standard reaction, $1 \mu \mathrm{g}$ genomic DNA was subjected to 30 cycles of polymerase chain reaction using 2.5 units of Taq Polymerase (Perkin Elmer-Cetus) and DPB1 specific primers $259 \mathrm{C}$ and $257 \mathrm{C}$ at a $1 \mu \mathrm{mol} / \mathrm{l}$ concentration as previously described. ${ }^{16}$ These primers span a 291 base pair segment encoding the hypervariable regions of the DP $\beta$ chain responsible for allelic variation. Each cycle consisted of $95^{\circ} \mathrm{C}$ denaturation $(1.3$ minutes $), 55^{\circ} \mathrm{C}$ annealing (two minutes), and $72^{\circ} \mathrm{C}$ extension (three minutes), except for the initial denaturation step $\left(95^{\circ} \mathrm{C}\right.$ for 4.3 minutes) and the last extension step $\left(72^{\circ} \mathrm{C}\right.$ for 10 minutes $)$.

\section{ANALYSIS OF POLYMERASE CHAIN REACTION}

AMPLIFICATION PRODUCTS

Ten per cent of each polymerase chain reaction product was electrophoresed and blotted onto Hybond-N according to standard procedures

TABLE I Oligonucleotide probes defining DPw1 associated nucleotide sequences

\begin{tabular}{llcl}
\hline Name & Sequence & $\begin{array}{l}\text { Amino } \\
\text { acids }\end{array}$ & $\begin{array}{l}\text { DPB allele } \\
\text { specificity }\end{array}$ \\
\hline 258C & 5'TACGTGTACCAGGGACGGC & $7-12$ & $1,15,18$ \\
401D & 5'GTCTGCATACCCTGTCC & $74-78$ & $1,3,7,8,9,10,12,14$ \\
402D & 5'AGGAGTACGCGCGCTTC & $34-38$ & $1,11,13,15$ \\
849D & 5'GAGCTGGTCGGGCCCAT & $84-88$ & 15,18 \\
\hline
\end{tabular}

TABLE II HLA class II genotype and oligonucleotide data in 23 patients with dermatitis herpetiformis

\begin{tabular}{|c|c|c|c|c|c|c|c|}
\hline \multirow[t]{2}{*}{ Patient } & \multicolumn{3}{|c|}{ HLA class II genotype } & \multicolumn{4}{|c|}{ Oligonucleotide data } \\
\hline & $D R$ & $D Q$ & $D P$ & $258 C$ & $401 D$ & $402 D$ & $849 D$ \\
\hline $\begin{array}{l}\text { FB } \\
\text { JB } \\
\text { DC1 } \\
\text { JC1 } \\
\text { JC2 } \\
\text { DC2 } \\
\text { DC3 } \\
\text { MC } \\
\text { EF } \\
\text { EG } \\
\text { KH } \\
\text { DH } \\
\text { MJ } \\
\text { PK } \\
\text { MK } \\
\text { SM } \\
\text { AR } \\
\text { BR } \\
\text { RS } \\
\text { CS } \\
\text { JS } \\
\text { BT } \\
\text { WT }\end{array}$ & $\begin{array}{l}3,7 \\
3,7 \\
2,3 \\
3,3 \\
3,7 \\
2,3 \\
2,3 \\
5,7 \\
2,3 \\
3, w 8 \\
3, w 6 \\
3, w 6 \\
3,7 \\
3,7 \\
3, w 6 \\
3, w 6 \\
3,7 \\
2,3 \\
5,7 \\
2,3 \\
3,4 \\
3,3 \\
1,3\end{array}$ & $\begin{array}{l}2 a 2 b \\
2 a 2 b \\
1 b 2 a \\
2 a 2 a \\
2 a 2 b \\
1 b 2 a \\
1 a 2 a \\
2 b 3 b \\
1 b 2 a \\
2 a 3 a \\
1 a 2 a \\
1 b 2 a \\
2 a 2 b \\
2 a 2 b \\
1 a 2 a \\
1 b 2 a \\
2 a 2 b \\
1 b 2 a \\
2 b 3 b \\
1 b 2 a \\
2 a 3 a \\
2 a 2 a \\
1 a 2 a\end{array}$ & $\begin{array}{l}1,1 \\
1,4 \\
1,4 \\
1,4 \\
4,3 / 6 \\
4,3 / 6 \\
1,2 \\
4,4 \\
1,4 \\
4,4 \\
2,5 \\
4,4 \\
1,5 \\
3 / 6, M 1.8 \\
4,3 / 6 \\
4,3 / 6 \\
2,4 \\
4,3 / 6 \\
4,4 \\
4,4 \\
1,2 \\
4,3 / 6 \\
1,4\end{array}$ & $\begin{array}{l}+ \\
+ \\
+ \\
+ \\
- \\
+ \\
- \\
+ \\
- \\
- \\
+ \\
- \\
- \\
- \\
- \\
- \\
+ \\
- \\
+\end{array}$ & $\begin{array}{l}+ \\
+ \\
+ \\
+ \\
+ \\
+ \\
+ \\
+ \\
+ \\
- \\
- \\
+ \\
+ \\
+ \\
+ \\
+ \\
+ \\
- \\
- \\
+ \\
+ \\
+\end{array}$ & $\begin{array}{l}+ \\
+ \\
+ \\
+ \\
- \\
\overline{+} \\
\pm \\
+ \\
- \\
- \\
- \\
+ \\
- \\
- \\
- \\
- \\
- \\
- \\
+ \\
+\end{array}$ & $\begin{array}{l}- \\
- \\
z \\
z \\
z \\
z \\
z \\
z \\
= \\
z \\
z \\
z \\
- \\
- \\
- \\
-\end{array}$ \\
\hline
\end{tabular}

TABLE III Comparison of $H L A, D R, D Q$, and $D P$ phenotype frequencies among dermatitis herpetiformis $(D H)$ patients and control subjects. Fisher's p values, relative risks $(R R)$, and aetiologial fractions $(A F)$ are given below for statistically significant positive associations

\begin{tabular}{|c|c|c|}
\hline Type & $\begin{array}{l}D H(n=23) \\
\%(N o)\end{array}$ & $\begin{array}{l}\text { Control }(n=53) \\
\%(\mathrm{No})\end{array}$ \\
\hline $\begin{array}{l}\text { DR: } \\
1 \\
2 \\
3^{\star} \\
4 \\
5 \\
\text { w6 } \\
7 \\
\text { w8 }\end{array}$ & $\begin{array}{c}- \\
26(6) \\
91(21) \\
4(1) \\
9(2) \\
17(4) \\
35(8) \\
4(1)\end{array}$ & $\begin{array}{c}26(14) \\
30(16) \\
28(15) \\
28(15) \\
13(7) \\
24(13) \\
28(15) \\
6(3)\end{array}$ \\
\hline $\begin{array}{l}\text { w1 } \\
\text { w2† } \\
\text { w3 }\end{array}$ & $\begin{array}{c}48(11) \\
100(23) \\
17(4)\end{array}$ & $\begin{array}{l}66(35) \\
40(21) \\
47(25)\end{array}$ \\
\hline $\begin{array}{l}\text { DP: } \\
\text { w1 } \\
\text { w2 } \\
\text { w3/6 } \\
\text { w4 } \\
\text { w5 } \\
\text { M1.8 }\end{array}$ & $\begin{array}{c}39(9) \\
17(4) \\
26(6) \\
70(16) \\
9(2) \\
4(1)\end{array}$ & $\begin{array}{c}11(6) \\
25(13) \\
49(26) \\
81(43) \\
9(5) \\
6(3)\end{array}$ \\
\hline
\end{tabular}

${ }^{\star} \mathrm{p}=1.9 \times 10^{-7}, \mathrm{RR}=22, \mathrm{AF}=0.88 .+\mathrm{p}=1.7 \times 10^{-7}, \mathrm{RR}=68$, $\mathrm{AF}=1 \cdot 00 . \mp \mathrm{p}=0 \cdot 008, \mathrm{RR}=4 \cdot 8, \mathrm{AF}=0.32$.

(Amersham). Duplicate filters with adjusted polymerase chain reaction products were each hybridised with one of a series of four sequence specific oligonucleotide probes. Probe specificities are given in Table I. Subjects who are positive with 258C, 401D, and 402D and negative with $849 \mathrm{D}$ have the DPB1 allele which is associated with the DPwl specificity.

Oligonucleotide probes were end labelled, purified, hybridised, and washed according to published methods. ${ }^{23}$ Hybridisation was carried out at $52^{\circ} \mathrm{C}(19 \mathrm{mer}$ oligonucleotide $258 \mathrm{C})$ or $48^{\circ} \mathrm{C}$ (17mer oligonucleotides 401D, 402D, and 849D) for three hours followed by stringent washing at $56^{\circ} \mathrm{C}(258 \mathrm{C})$ or $52^{\circ} \mathrm{C}(401 \mathrm{D}, 402 \mathrm{D}$, and $849 \mathrm{D})$ in $3 \cdot 2 \mathrm{M}$ tetramethylammonium chloride (Fluka) $1 \%$ sodium dodecyl sulphate. Filters were autoradiographed for two to 12 hours at $-70^{\circ} \mathrm{C}$.

Statistical comparison of patient and control subject data was carried out using Fisher's exact test. Relative risks and aetiological fractions were calculated using the Woolf-Haldane method.

\section{Results}

DR and DQ genotypes were assigned according to the restriction fragment pattern seen from Taql digests of genomic DNA hybridised with DRB, DQB, and DQA cDNA probes. ${ }^{24}$ DP genotypes were assigned according to the restriction pattern obtained using Mspl and DPB1, and Taql and DPA1. ${ }^{25}$ Genotypes assigned to the dermatitis herpetiformis patients are shown in Table II. M1.8 is a locally defined allele based on the presence of both $3.0 \mathrm{~kb}$ and $1.8 \mathrm{~kb}$ Mspl DPB1 fragments. Comparisons of the distribution of DR, DQ, and DP genotypes in dermatitis herpetiformis patients and control subjects are shown in Table III, with the relative risks and aetiological fractions showing the strength of association. Since the intention of this study was to compare the associations of dermatitis herpetiformis with coeliac disease, the $p$ values have not been corrected.

The strongest association is seen with HLA- 


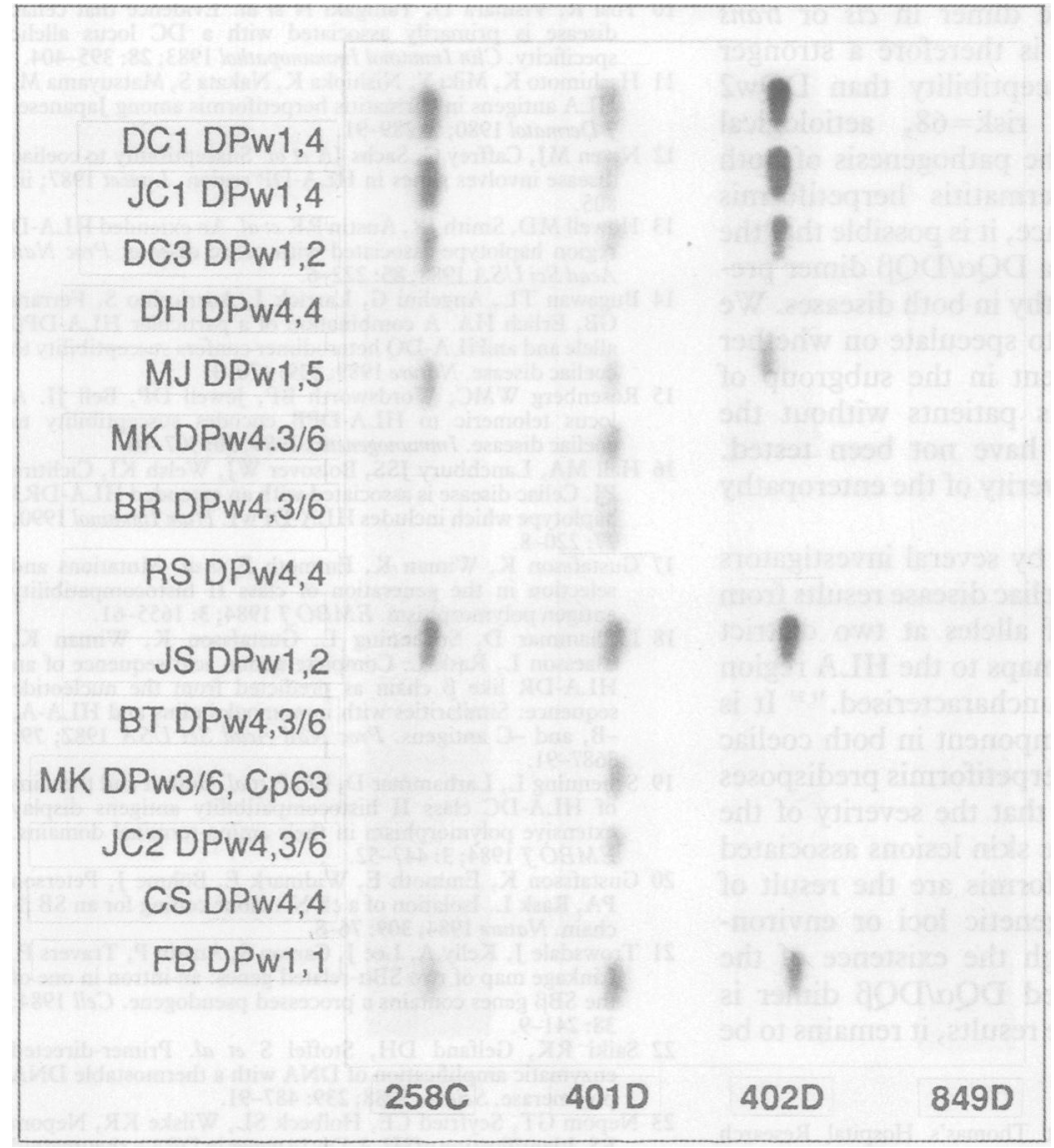

Southern blot analysis of polymerase chain reaction amplified DPBI products from $14 D P$ genotyped dermatitis herpetiformis patients. Duplicate filters were hybridised with one of a series of four sequence specific oligonucleotide probes. Probe specificities are as follows: $258 \mathrm{C}$ is specific for $D P B 1,15$ and $18 ; 401 D$ is specific for $D P B 1,3,7,8,9,10,12$, and $14 ; 402 D$ is specific for DPB1,11,13, and 15 and $859 D$ is specific for DPB15 and $18 . C p 63$ has been given the local allele designation M1.8.

DR3 and DQw2. Twenty one of $23(91 \%)$ dermatitis herpetiformis patients are DR3 positive compared with $28 \%$ of control subjects (Fisher's exact test $\mathrm{p}=1.9 \times 10^{-7}$, aetiological fraction $=0 \cdot 88$ ). Twenty of the 21 DR3 positive patients have the Taql restriction fragment length polymorphism pattern associated with the A1 B8 DR3 haplotype. ${ }^{26}{ }^{24}$ The association with DQw2 is stronger - all 23 patients type as DQw2 compared with $40 \%$ of control subjects $(\mathrm{p}=1 \cdot 7 \times$ $10^{-7}$, aetiological fraction $\left.=1 \cdot 00\right)$. Both these associations are comparable with those reported for coeliac disease. DP genotyping shows a significant increase in the frequency of DPwl in dermatitis herpetiformis patients compared with control subjects (Table III). Nine of 23 dermatitis herpetiformis patients typed as DPwl compared with 6 of 53 controls $(p=0.008$, aetiological fraction $=0 \cdot 32$ ). We and others have previously shown a similar association with coeliac disease $^{271516}$ and it has also been deduced for dermatitis herpetiformis (from primed lymphocyte typing data). ${ }^{8}$ The Figure shows the hybridisation pattern of our four oligonucleotides in DP genotyped dermatitis herpetiformis patients. To confirm the restriction fragment length polymorphism determined DPwl genotype, oligonucleotide probes targeting specific DPwl associated DPB1 sequences were used (Table I). The DPwl genotype assigned by restriction fragment length polymorphism analysis corresponds exactly with the pattern of hybridisation of the oligonucleotides assigned to the DPB1 allele.

Independently, we have shown the DPB1 association at the molecular level, using both restriction fragment length polymorphisms and oligonucleotide analysis. Since we have shown that DR3 and DPwl exist on an extended haplotype which is raised in coeliac disease, the results from this study suggest that the same extended haplotype is also highly represented in dermatitis herpetiformis.

\section{Discussion}

There is firm evidence for a shared genetic basis for the gluten sensitive enteropathy seen in coeliac disease and dermatitis herpetiformis. The strongest clue so far to understanding the shared pathogenesis is the mapping of susceptibility to the HLA class II region of the human major histocompatibility complex. This region contains genes coding for heterodimeric transmembrane glycoproteins which determine the magnitude and specificity of immune responses. ${ }^{28}$ Coeliac disease and dermatitis herpetiformis share a similar immunopathology, namely $\mathrm{T}$ lymphocyte infiltration into the small intestinal intraepithelial layer and increased anti-gliadin antibody concentrations. The fact that the skin disease of many dermatitis herpetiformis patients can be controlled by a gluten free diet is further evidence of a relation. It is reasonable, therefore, to suppose that HLA class II genes directly influence specific immune responses leading to the characteristic mucosal damage. The first task in understanding the mechanistic link is to identify the HLA class II locus responsible. This is complicated by the extreme linkage disequilibrium shown by the A1 B8 DR3 DQw2 haplotype associated with both coeliac disease and dermatitis herpetiformis.

In this study we have examined molecular polymorphisms associated with $\mathrm{DR}, \mathrm{DQ}$, and DP loci among dermatitis herpetiformis patients and control subjects in order to isolate the primary susceptibility allele. Although dermatitis herpetiformis was significantly associated with DR3, DQw2, and DPwl, the strongest association is with DQw2, which must be considered the candidate allele for this disease. Since DR3, DPw1, and DQw2 are in linkage disequilibrium, the increase in DR3 and DPw1 can be explained by their existence on an extended haplotype which is highly represented in the disease population. This conclusion is further strengthened by recent reports that the HLA molecule most consistently associated with coeliac disease is a specific DQw2 DQ $\alpha / \beta$ heterodimer encoded in cis arrangement on a DR3 haplotype. ${ }^{29}{ }^{30}$ Since the same DQ $\alpha$ allele is also shared between DR3 and DR5 haplotypes, an identical transassociated $\mathrm{DQ} \alpha / \mathrm{DQ} \beta$ dimer could be expressed by DR5, 7 subjects. Our data on dermatitis herpetiformis patients fits this model exactly. The two patients who do not type as DR3 are DR5, 7 and are capable of expressing the transassociated DQ $\alpha / \mathrm{DQ} \beta$ dimer. Thus $100 \%$ of dermatitis herpetiformis patients in contrast to $32 \%$ of control subjects $\left(p=5 \cdot 2 \times 10^{9}\right.$, relative risk $=98$, aetiological fraction $=1 \cdot 00$ ) have the 
potential to express the dimer in cis or trans configuration, and this is therefore a stronger marker for disease susceptibility than $D Q w 2$ $\left(p=1 \cdot 7 \times 10^{-7}\right.$, relative risk $=68$, aetiological fraction $=1 \cdot 00$ ). Since the pathogenesis of both coeliac disease and dermatitis herpetiformis involves gluten intolerance, it is possible that the shared association with a $\mathrm{DQ} \alpha / \mathrm{DQ} \beta$ dimer predisposes to the enteropathy in both diseases. We are not, however, able to speculate on whether this association is present in the subgroup of dermatitis herpetiformis patients without the enteropathy since they have not been tested. What determines the severity of the enteropathy is not known.

It has been proposed by several investigators that predisposition to coeliac disease results from recessive inheritance of alleles at two district genetic loci. One locus maps to the HLA region while the other one is uncharacterised. ${ }^{31}{ }^{32}$ It is likely that the HLA component in both coeliac disease and dermatitis herpetiformis predisposes to the enteropathy and that the severity of the mucosal damage and the skin lesions associated with dermatitis herpetiformis are the result of involvement of other genetic loci or environmental factors. Although the existence of the postulated transassociated $\mathrm{DQ} \alpha / \mathrm{DQ} \beta$ dimer is strongly indicated by the results, it remains to be proved biochemically.

MAH is supported by the St Thomas's Hospital Research Endowments and the Coeliac Society of Great Britain. PJC is a Wellcome Senior Clinical Research Fellow.

1 Scott BB, Losowsky MS. Patchiness and mucosal abnormality in coeliac disease (CD) and dermatitis herpetiformis (DH). in coeliac disease

2 Katz SI, Falchuk ZM, Dahl MV, Rogentine GN, Strober W HL-AB: a genetic link between dermatitis herpetiformis an gluten-sensitive enteropathy. $\mathcal{F}$ Clin Invest 1972; 51: 2977 80.

3 White AG, Barnetson R St.C, Da Costa JAG, McClelland DBL. The incidence of HL-A antigens in dermatitis herpetiformis. Br f Dermatol 1973; 89: 133-6.

4 Seah PP, Fry L, Kearney JW et al. A comparison of histocompatibility antigens in dermatitis herpetiformis and adult coeliac disease. Br 7 Dermatol 1976; 94: 131-8.

5 Solheim BG, Ek J, Thune PO et al. HLA antigens in dermatitis herpetiformis and coeliac disease. Tissue Antigens 1976; 7: 57-9.

6 Park MS, Terasaki PI, Ahmed AP, Zone J. The $90 \%$ incidence of HLA antigen (Te24) in dermatitis herpetiformis. Tissue Antigens $1983 ; 22: 263-6$

7 Sachs JA, Awad J, McCloskey D et al. Different HLA associated gene combinations contribute to susceptibility for coeliac disease and dermatitis herpetiformis. Gut 1986; 27 : 515-20.

8 Hall RP, Sanders ME, Duquesnoy RJ, Katz SI, Shaw S Alterations in HLA-DP and HLA-DQ antigen frequency in patients with dermatitis herpetiformis. 7 Invest Dermatol 1989; 93: 501-5.

9 Demarchi M, Carbonara A, Ansaldi $\mathrm{N}$ et al. HLA-DR3 and DR7 in coeliac disease: immunogenetic and clinical aspects. Gut 1983; 24: 706-12.
10 Tosi R, Vismara D, Tanigaki $\mathrm{N}$ et al. Evidence that celiac disease is primarily associated with a DC locus allelic specificity. Clin Immunol Immunopathol 1983; 28: 395-404.

11 Hashimoto K, Miki Y, Nishioka K, Nakata S, Matsuyama M. HLA antigens in dermatitis herpetiformis among Japanese. 7 Dermatol 1980; 7: 289-91.

12 Niven MJ, Caffrey C, Sachs JA et al. Susceptibility to coeliac disease involves genes in HLA-DP region. Lancet 1987; ii: disease 805 .

13 Howell MD, Smith JR, Austin RK et al. An extended HLA-D region haplotype associated with celiac disease. Proc Natl Acad Sci USA 1988; 85: 222-6.

14 Bugawan TL, Angelini G, Larrick J, Aurricchio S, Ferrara $\mathrm{GB}$, Erlich HA. A combination of a particular HLA-DP allele and an HLA-DQ heterodimer confers susceptibility to coeliac disease. Nature 1989; 339: 470-3.

15 Rosenberg WMC, Wordsworth BP, Jewell DP, Bell JI. A locus telomeric to HLA-DPB encodes susceptibility to coeliac disease. Immunogenetics 1989; 30: 307-10.

16 Hall MA, Lanchbury JSS, Bolsover WJ, Welsh KI, Ciclitira PJ. Celiac disease is associated with an extended HLA-DR3 haplotype which includes HLA-DPwl. Hum Immunol 1990; 27: $220-8$.

17 Gustafsson K, Wiman K, Emmoth E et al. Mutations and selection in the generation of class II histocompatibility
antigen polymorphism. $E M B O \mathcal{f} 1984 ; 3: 1655-61$.

18 Larhammar D, Schenning L, Gustafsson K, Wiman $K$, Claesson L, Rask L. Complete amino acid sequence of an HLA-DR like $\beta$ chain as predicted from the nucleotide sequence: Similarities with immunoglobulins and HLA-A $-\mathrm{B}$, and $-\mathrm{C}$ antigens. Proc Natl Acad Sci USA 1982; 79: 3687-91.

19 Schenning L, Larhammar D, Bill P et al. Both $\alpha$ and $\beta$ chains of HLA-DC class II histocompatibility antigens display extensive polymorphism in their amino-terminal domains. EMBOF $1984 ; 3: 447-52$.

20 Gustafsson K, Emmoth E, Widmark E, Böhme J, Peterson PA, Rask L. Isolation of a cDNA clone coding for an SB $\beta$ chain. Nature 1984; 309: 76-8

21 Trowsdale J, Kelly A, Lee J, Carson S, Austin P, Travers P. Linkage map of two $S B \alpha$-related genes: an intron in one of the SB $\beta$ genes contains a processed pseudogene. Cell 1984 38: $241-9$.

22 Saiki RK, Gelfand DH, Stoffel S et al. Primer-directed enzymatic amplification of DNA with a thermostable DNA polymerase. Science 1988; 239: 487-91.

23 Nepom GT, Seyfried CE, Holbeck SL, Wilske KR, Nepom BS. Identification of HLA-Dw 14 genes in DR4 + rheumatoid arthritis. Lancet 1986; ii: 1002-5.

24 Bidwell JL, Bidwell EA, Laundy GJ, Klouda PT, Bradley BA. Allogenotypes defined by short $\mathrm{DQ} \alpha$ and $\mathrm{DQ} \beta \mathrm{cDNA}$ probes correlate with and define splits of HLA-DQ seroprobes correlate with and define splits of HLA-DQ

25 Hyldig-Nielsen JJ, Morling N, Odum N et al. Restriction fragment length polymorphism of the HLA-DP subregion and correlations to HLA-DP phenotypes. Proc Natl Acad Sci USA 1987; 84: 1644-8.

26 Bontrop RE, Tilanus $M$, Mikulski M, Van Eggermond $M$, Termijtelen A, Giphart $M$. Polymorphisms within the HLA-DR3 haplotypes. Immunogenetics 1986; 23: 401-5.

27 Kagnoff MF, Harwood JI, Bugawan TL, Erlich HA. Structural analysis of the HLA-DR, $-D Q$, and -DP alleles on the celiac disease associated HLA-DR3 (DRw17) haplotype. Proc Natl Acad Sci USA 1989; 86; 6274-8.

28 Kaufman JF, Auffray C, Korman AJ, Shackelford DA Strominger I. The class II molecules of the human and murine major histocompatibility complex. Cell 1984; 36: 1 3 .

29 Roep BO, Bontrop RE, Pena AS, van Eggermond MCJA, van Rood JJ, Giphart MJ. An HLA-DQ alpha allele identified a DNA and protein level is strongly associated with celiac disease. Hum Immunol 1988; 23: 271-9.

30 Sollid LM, Markussen G, Ek J, Gjerde H, Vartdal F, Thorsby E. Evidence for a primary association of celiac disease to particular HLA-DQ $\alpha / \beta$ heterodimer. $\mathcal{F}$ Exp Med $1989 ; 169$ 345-50.

31 Pena AS, Mann DL, Hague NE. Genetic basis of gluten sensitive enteropathy. Gastroenterology 1978; 75: 230-5.

32 Greenberg DA, Hodge SE, Rotter JI. Evidence for recessive and against dominant inheritance at the HLA - "linked" locus in coeliac disease. Am 7 Hum Genet 1982; 34: 263-77. 